\title{
La miopía en la gestión frente a la innovación en una oferta de mercado
}

\section{CLEMENCIA GODOY PAVA}

\section{RESUMEN}

A través del artículo se hace un análisis de la innovación en relación con la oferta de mercado y cómo es manejada en mercadeo, para luego establecer la estrecha relación que el tema tiene con el modo de gestión en las empresas, profundizando en la manera tradicional como la gestión ha sido asumida y aplicada y sus implicaciones para el logro de la innovación. Finalmente, lo anterior se vincula con la creación de valor a partir del papel del consumidor como prosumidor, desde el enfoque del marketing holístico, dada la importancia y repercusión que el modo de gestión también tiene para este enfoque.

\section{PALABRAS CLAVE}

Innovación de oferta de mercado, innovación de gestión, creación de nuevos productos, niveles de innovación, equipos transfuncionales, estilo de dirección, participación, consumidor - prosumidor, ventaja competitiva,
El presente artículo se centra en la innovación en el desarrollo de ofertas de mercado a partir de la propuesta de los teóricos del marketing y su relación con el concepto de gestión, expuesto también desde la perspectiva de la innovación, dada la importancia de ambos conceptos como soportes fundamentales para el logro de ventajas competitivas y de la creación de valor.

Es necesario aclarar que en el contexto del presente artículo, el concepto de empresa se define como "una organización de propiedad privada que atiende a sus clientes para obtener utilidades" ${ }^{1}$; estas últimas se entienden como la compensación por el riesgo asumido al ofrecer a la venta productos; y se calculan restando del total de gastos el total de ingresos.

\section{Innovación y oferta de mercado}

En cuanto a la innovación en relación con el concepto de oferta de mercado en mecadeo, es preciso aclarar lo siguiente: "En mercadeo el concepto de nuevos productos-servicios tiene diferentes significados dependiendo de con qué se le relacione: con el mercado, con la empresa o con el consumidor"2.

Para un mercado, un producto-servicio es totalmente nuevo cuando es realmente diferente a otros ya presentes en el mercado; en este caso se habla de "innovación total". Se trata de productos originales, que crean un mercado nuevo, inician su ciclo de vida y no tienen competencia directa cuando salen al mercado ${ }^{3}$.

1 KERIN, Roger, BERKOWITZ, Eric, HARTLEY, Steven, RUDELINS, William. Marketing. México: Mc Graw Hill, 2004.7 ed. p.34.

2 TALAYA, Agueda. Principios de Marketing. Madrid: ESIC, 1996. p. 342.

3 GUILTINAN, Joseph y GORDON, Paul. Marketing. Bogotá: McGraw Hill, 2004. P. 199.

KOTLER, Philip. Dirección de Marketing. Barcelona: Paidós, 2002. p. 372.

PRIDE William y FERREL, O C. Marketing: Conceptos y Estrategias. Bogotá: Mc Graw Hill, 1997. 9 ed. p. 305.

LAMB, Charles W Jr. Marketing. México: Thomson, 1998. 4 ed. p. 302.

TALAYA, Op. cit., p. 342. 
Para una empresa, un producto-servicio es nuevo cuando ofrece a un mercado un producto que antes no ofrecía, tal es el caso de la creación de nuevas líneas de producto; cuando encuentra atributos o características que le permiten diferenciar un producto de la competencia y hace extensiones/adiciones a las líneas de productos ya existentes; tanto con la creación de nuevas líneas, como con la extensión de las mismas, la empresa entra en mercados ya establecidos ${ }^{4}$.

Para un consumidor, un producto-servicio es nuevo cuando lo percibe diferente con respecto a un conjunto de características concretas (por ejemplo: el rendimiento o la apariencia) ${ }^{5}$.

\section{Clemencia Godoy Pava}

Psicóloga de la Universidad Católica de Colombia. Especialista en Gestión y Evaluación Curricular y Magíster en Administración de Empresas de la Universidad Externado de Colombia. Actualmente vinculada al Politécnico Grancolombiano como docente investigadora en el Programa de Mercadeo y Publicidad en la Facultad de Ciencias de la Comunicación y Artes y a Quanta Research International como investigadora. Ha sido docente de las universidades Externado, Jorge Tadeo Lozano, Javeriana y Antonio Nariño. Cuenta además con experiencia de 20 años en empresas públicas y privadas.

En resumen, la creación de nuevos productos se puede clasificar en las siguientes categorías: productos nuevos que crean un mercado totalmente nuevo; nuvas líneas de productos que permiten a una empresa ingresar a un mercado existente; incorporación de productos a las líneas, es decir, productos nuevos que complementan las líneas ya existentes; mejoras o revisiones de los productos ya existentes, o sea productos nuevos con un mejor rendimiento o que el mercado los percibe de manera más positiva y por esto reemplazan a los anteriores; reposicionamiento de productos que ya están en el mercado en nuevos mercados o segmentos; reducción de costos a través de productos nuevos que tienen la misma utilidad de otros que ya están en el mercado, pero a un costo más bajo ${ }^{6}$.

Cada una de las categorías anteriores supone niveles de innovación diferentes, de forma que solamente aquellos productos que crean un mercado nuevo e inician su ciclo de vida, son los realmente innovadores. Los demás, podría decirse que son productos que ya existen y son mejorados.

En consecuencia, puesto que la mayor parte de la actividad de innovación en las empresas se centra en la mejora de productos existentes y solamente en una mínima proporción en productos realmente originales que crean nuevos mercados, lo ideal apunta entonces a la creación de este último tipo de productos que representen una gran ventaja competitiva, que hagan probable de manera contundente su éxito en el mercado y que, por ende, faciliten el establecimiento de relaciones de largo plazo con los consumidores, más aún cuando se sabe que la creación de nuevos productos basada en la mejora de productos existentes, generalmente otorga a la empresa ventajas temporales, puesto que la competencia puede copiar rápidamente los productos ${ }^{7}$.

Según Kotler "todas las empresas deben preocuparse por desarrollar productos nuevos: en ello se basa el futuro de la empresa. Se deben crear productos que reemplacen a los antiguos a fin de mantener o crear un importante volumen de ventas", de lo contrario, las amenazas son evidentes: o los productos ya no responden a las necesidades de los consumidores, o son superados por nuevas tecnologías, o su ciclo de vida se vuelve cada vez más corto, o la competencia nacional y extranjera es cada vez mayor ${ }^{8}$.

\footnotetext{
4 GUILTINAN y GORDON, Op. Cit, p. 199.

KERIN, BERKOWITZ, HARTLEY y RUDELINS, Op. cit, p. 304.

KOTLER, Op. cit., p. 372.

5 MONTAÑA, Jordi. Marketing de nuevos productos. Diseño, desarrollo y lanzamiento. Barcelona: Hispano Europea, 1990. p. 17.

TALAYA, Op. cit., p. 342.

6 GUILTINAN Y GORDON, Op. Cit., p.199.

KOTLER, Op. Cit., p. 372.

LAMB, Op. Cit., p. 302.

MONTANA, Op. Cit., p. 18

7 KOTLER, Op. Cit., p. 375.

8 Ibid., p. 372.
} 
Para varios autores, la actividad innovadora para la creación de productos en toda empresa, debe tener un marco de referencia dado por la empresa, desde la misma estrategia corporativa, que involucrando la estrategia de mercadeo, se enfoque de manera permanente al aporte de valor al cliente, para lo cual define y busca mecanismos para la generación de innovación a partir de sus empleados ${ }^{9}$.

La innovación y el desarrollo de productos nuevos es de hecho más efectivo cuando varios departamentos de la empresa (investigación y desarrollo, ingeniería, producción, finanzas, mercadeo) trabajan conjuntamente con este propósito; generalmente las empresas proponen la estructura de "equipos transfuncionales", compuestos por un reducido número de personas de varios departamentos que comparten sus conocimientos y experiencias para el logro de este objetivo ${ }^{10}$.

Algunos autores van más allá y plantean la necesidad de involucrar también a clientes y proveedores, en línea con un proceso de "marketing" más holístico para explorar, crear y distribuir valor al consumidor y en consecuencia, lograr ventajas competitivas para la empresa ${ }^{11}$.

Los equipos transfuncionales de Boeing no solo incluyen a empleados de diferentes áreas funcionales de la empresa, sino también a proveedores y clientes. Después de escuchar a pasajeros, un equipo transfuncional de la compañía participó en el desarrollo del Boeing 777, con innovaciones que brindan valor a los clientes ${ }^{12}$.

¿Qué es entonces lo que puede dar soporte a una oferta de mercado realmente innovadora, que haga viable relaciones de largo plazo con los consumidores y que permita construir y mantener una ventaja competitiva? Es posible que la respuesta sea: la innovación en la gestión.

\section{Innovación y gestión}

Según Gary Hamel:

Una innovación de gestión puede ser definida como un marcado alejamiento de los principios, procesos y prácticas tradicionales de gestión o como un alejamiento de las formas organizacionales acostumbradas que altera significativamente la forma en como realiza el trabajo de gestión. Puesto en términos simples, la innovación de gestión cambia el modo como los ejecutivos hacen lo que hacen ${ }^{13}$.

En relación con lo anterior, vale la pena hacer las siguientes consideraciones:

Tradicionalmente las empresas han diseñado su estrategia corporativa teniendo en cuenta las diferentes áreas operativas, sobre el supuesto de que la estrategia de por sí tiene un hilo conductor e integrador que posibilita la contribución de cada una de ellas, pero en la práctica la condición es otra: el área que parecería tener preponderancia es la financiera, mientras que la de menor incidencia es la de mercadeo. Esta condición es clara en la medida en que los recursos de dinero tienen que ver con toda la empresa, y es una de las razones por las cuales, en gran parte, las decisiones están centralizadas en esta área, lo cual le limita posibilidades al área de mercadeo, que más que ninguna otra área, con cierta regularidad, debe enfrentar situaciones inesperadas dadas las demandas que le hace el entorno externo con el que está en permanente contacto.

9 GUILTINAN y GORDON, Op. Cit., p. 200 y 203.

KERIN, BERKOWITZ, HARTLEY y RUDELINS, Op. Cit., p. 298.

KOTLER, Op. Cit., p.375.

LAMB, Op. Cit., p.303.

TALAYA, Op. Cit., p.347.

10 KOTLER, Op. Cit., p. 375

LAMB, Op. Cit., p. 303.

ULRICH, Karl y ESPPINGER, Steven. Diseño y desarrollo de productos. Enfoque multidisciplinario. México: Mc Graw Hill, 2004.3 ed. p.3.

11 KERIN, Op. Cit., p. 36.

12 KOTLER, Philip. El marketing se mueve. Barcelona: Paidós, 2002. p. 58

13 HAMEL, Gary. "Innovación de Gestión". Harvard Business Review. México. Vol. 48, Tomo 2 (febrero. 2006); p. febrero, 2006 ; p. 66.

Gary Hamel es fundador y presidente de Strategos, compañía dedicada a ayudar a sus clientes a desarrollar estrategias revolucionarias, y profesor visitante de administración estratégica e internacional en la Escuela de Economía de Londres. El Journal of Business Strategy hace poco incluyó al profesor Hamel entre las 25 primeras personalidades del siglo xx. 
La preocupación por los costos acentúa la tendencia a la estandarización de los productos, lo que a largo plazo genera "conformidad" y "comodidad", con lo ya conocido, restando oportunidad a la innovación ${ }^{14}$.

Una prueba de esto son muchos de los productos presentes actualmente en el mercado: existe una gran oferta, pero si se mira atentamente, varía en los mismos aspectos, lo que termina por hacer que los productos sean muy similares.

El estilo de dirección, en gran medida autocrático, acapara la toma de decisiones y ubica la responsabilidad del desarrollo y avance de la empresa particularmente en el nivel directivo.

La mayoría de las grandes corporaciones todavía se parece demasiado a las monarquías y muy poco a las democracias. Con el poder político concentrado en las manos de unas cuantas decenas de altos ejecutivos y con poco margen para la experimentación local, no es de extrañar que las grandes empresas se encuentren atrapadas con tanta frecuencia detrás de la curva de cambio ${ }^{15}$.

La subestimación de los conocimientos y en general del potencial de cada miembro de la organización para contribuir a la construcción, desarrollo y mantenimiento de la ventaja competitiva, deja de lado uno de los insumos más valiosos con los que puede contar una empresa ${ }^{16}$.

Una gestión con un enfoque burocrático con el que se propone ajustar el comportamiento de los empleados a normas y requisitos, tiene como resultado la obediencia y los aportes, que bajo un marco de referencia convencional, no se salen de lo esperado ni de lo corriente, condición que es muy fácil de copiar por la competencia y que en muchas partes del mundo está disponible a través de mano de obra de menor costo, lo cual no permite crear una diferenciación realmente valiosa a partir de la cual se puedan crear ventajas competitivas importantes.

Para repeler las fuerzas de comoditización, una empresa debe ser capaz de entregar el tipo de valor único para el cliente que solo pueden crear los empleados que cada día aportan plenamente a su trabajo, su iniciativa, imaginación y celo ${ }^{17}$.
La tendencia marcada a buscar y copiar modelos de gestión cuya aplicación se hace bajo los referentes de éxito en otros tipos de países y cuya consecuencia obvia es la pérdida de recursos, genera además de desconcierto, falta de credibilidad entre los empleados de la empresa.

Muchas veces un nuevo enfoque de gestión administrativa crea tal entusiasmo por sus resultados de aplicación en otros medios, que no falta el directivo que la acoja, convirtiéndolo finalmente en algo temporal, que se sustituye en la medida en que aparece un nuevo enfoque, sin dar tiempo suficiente para sopesar los resultados a mediano y largo plazo ${ }^{18}$.

La preocupación principal por procesos operacionales que hagan eficiente la empresa, acapara la atención, dejandose de lado una estrategia empresarial más totalizadora que complemente y le dé sentido de continuidad y permanencia a un modo de gestión que refuerce la innovación/experimentación 19 .

Una prueba de esto es la inversión en investigación, desarrollo, pruebas de producción, etcétera, que bajo un ambiente de premura por las exigencias del mercado, hace que se realicen actividades sin una dirección integradora que las capitalice alrededor de la consecución de ventajas competitivas contundentes y duraderas; es decir, hay mayor preocupación por la eficiencia.

La teoría administrativa ofrece diversos enfoques sobre principios y procesos organizacionales que han hecho aportes para hacer gestión empresarial, pero es indudable que con los que prevalecen actualmente -enfoque tayloriano centrado en la tarea, enfoque burocrático centrado en normas y definición de funciones, estructura organizacional con criterio divisional, la mayoría de ellos esbozados a comienzos del siglo pasado en respuesta a las demandas del surgimiento de las grandes industrias en el mundo, no se lograría hacer una gestión innovadora que realmente contribuya a que una organización pueda conseguir su competitividad en un ambiente de cambio e incertidumbre característico del contexto empresarial actual y mucho menos acoger al consumidor como gestor y constructor de alternativas que respondan a sus necesidades y de esta forma, ganar un actor más que contribuya al diseño y desarrollo de ofertas de mercado innovadoras.

14 KOTLER, El márketing se mueve, Op cit., p. 21 - 22.

15 HAMEL, Op. Cit., p. 71

16 Ibid., p. $71-72$.

MOLANO, Mauricio. De la calidad total a la calidad integral. Bogotá : Bancarias y Financieras, 1992. p. 20.

17 HAMEL, Op. Cit., p. 71 - 72.

18 CÁMARA DE COMERCIO DE BOGOTÁ. Testimonios de gestión humana. Bogotá: Cámara de Comercio de Bogotá, 1999. p. 193.

19 HAMEL, Gary. Liderando la revolución. Bogotá: Norma, 2000. p. 388. 
La gestión entonces debe replantearse y renovarse, comenzando por los principios y los procesos que le atañen, y quizá la consideración más importante, es el hecho de buscarse y redefinirse a partir de lo que es la misma empresa interiormente, con todas sus fortalezas y debilidades desde la perspectiva de lo que quiere y necesita llegar a ser: un ente abierto, flexible, que al mismo tiempo que es capaz de integrar sus procesos, responda con rapidez a los cambios planteados por el entorno, pero más que nada, a partir de lo que es su gente, cuya capacidad de autorregulación e iniciativa, debe encontrar espacios que la lleven a participar y a aportar realmente, puesto que finalmente y de manera relevante, la construcción de ventajas competitivas, parte fundamentalmente de los mismos empleados de la empresa.

Para ilustrar desde la práctica las consideraciones expuestas, a continuación se presenta el caso de la Organización Corona, que adelantó un cambio profundo en sus empresas, mediante el desarrollo de procesos con el enfoque de calidad total. (Anexo A.)

La Organización Corona, se hizo consciente de que en la forma como sus empresas estaban funcionando, difícilmente le era posible tener niveles de productividad y competitividad indispensables para ser autosostenible, en un ambiente de apertura económica, por lo cual empezó a reflexionar sobre la forma en que podía conseguirlo.

Definió entonces los siguientes aspectos, como orientadores fundamentales para lograr sus propósitos: la concepción de organización como ente dinámico y atento a las exigencias de su entorno interno y externo, un modo de gestión participativo y el papel activo de los empleados como gestores directos de su trabajo.

A partir de esto diseñó el programa de cambio, recurriendo a la bibliografia actualizada sobre gestión, la experiencia sobre el tema en otros países y la experiencia propia, con el fin de capitalizar este conocimiento teniendo en cuenta siempre las necesidades y las características particulares de la Organización Corona, para hacer el programa congruente con su cultura.
El concepto de trabajo por proceso, se aplicó en los diferentes puestos de trabajo, lo que hizo que cada empleado se involucrara, se capacitara, concretara su aporte y entendiera la importancia del mismo, tanto para su trabajo como para el de otros; estimuló la generación de ideas y la reflexión. La concepción del trabajo fue más allá del logro de la eficiencia y adquirió importancia en términos de la misión colectiva de la Organización.

El ambiente integrador, socializador y gregario, que dio soporte a todo lo anterior, es también un indicador del cambio a un modo de gestión más abierto y participativo.

\section{Reflexiones sobre la gestión}

No se puede desconocer que las mismas empresas deben enfrentar aspectos bastante retadores:

- La búsqueda de orden a través de una estructura divisional que simultáneamente permita el contacto interdisciplinario para la construcción de alternativas, a pesar de las limitaciones inherentes a la misma especialización, que impone modos parciales de ver la realidad y con esto, una menor posibilidad de generar ideas.

- Una gestión enmarcada por la tradición y la costumbre, que estrecha las perspectivas para abordarla desde otros ángulos más innovadores.

- La dificultad para delegar y descentralizar la toma de decisiones y asumir modos participativos para adelantar la gestión.

- El establecimiento de confianza, credibilidad y cercanía, para generar un ambiente que realmente motive y estimule la autorregulación y la cooperación de la gente.

- La tendencia habitual de dar prioridad a lo financiero, lo que comúnmente restringe el desarrollo de proyectos propuestos por los mismos empleados, desestimulando de esta forma su participación y aportes.

Cabe igualmente mirar críticamente algunos principios de gestión, que según Gary Hamel, se han asumido de 
manera generalizada y se siguen asumiendo como verdades absolutas y que ameritan un examen cuidadoso, por el impacto negativo que tiene para toda empresa y la construcción de ventajas competitivas ${ }^{20}$ :

- "El cambio debe empezar desde la cúpula".

- "Se requiere una crisis para provocar el cambio".

- "Hace falta un líder fuerte para cambiar una empresa grande".

- "Para liderar el cambio, se necesita una agenda muy clara".

- "La gente está en su mayoría contra el cambio".

- "En cualquier cambio, siempre habrá ganadores y perdedores".

- "Se debe hacer que el cambio sea seguro para las personas".

- "Las organizaciones sólo pueden lidiar con una cierta cantidad de cambio 20 .
Estos principios de gestión aunque validados empíricamente, deben ser asumidos con cautela, dado que dentro del marco de una gestión innovadora cabe preguntarse si más que verdades absolutas, son más bien el resultado de la concentración del poder en directivos que no se apartan de la tradición y que prefieren acogerse a pautas establecidas desde hace muchos años que de una u otra forma generan "la tranquilidad de lo conocido" y con esto el "ahorro" de esfuerzo para encontrar maneras diferentes de asumir y manejar la realidad empresarial ${ }^{21}$.

El siguiente gráfico resume de manera general, la propuesta de Hamel para el logro de la innovación. En este punto vale la pena entrar en el tema de Marketing holístico y su propuesta sobre el papel de consumidor como "prosumidor" o cocreador de valor, tema para

\section{Grafico No. 1}

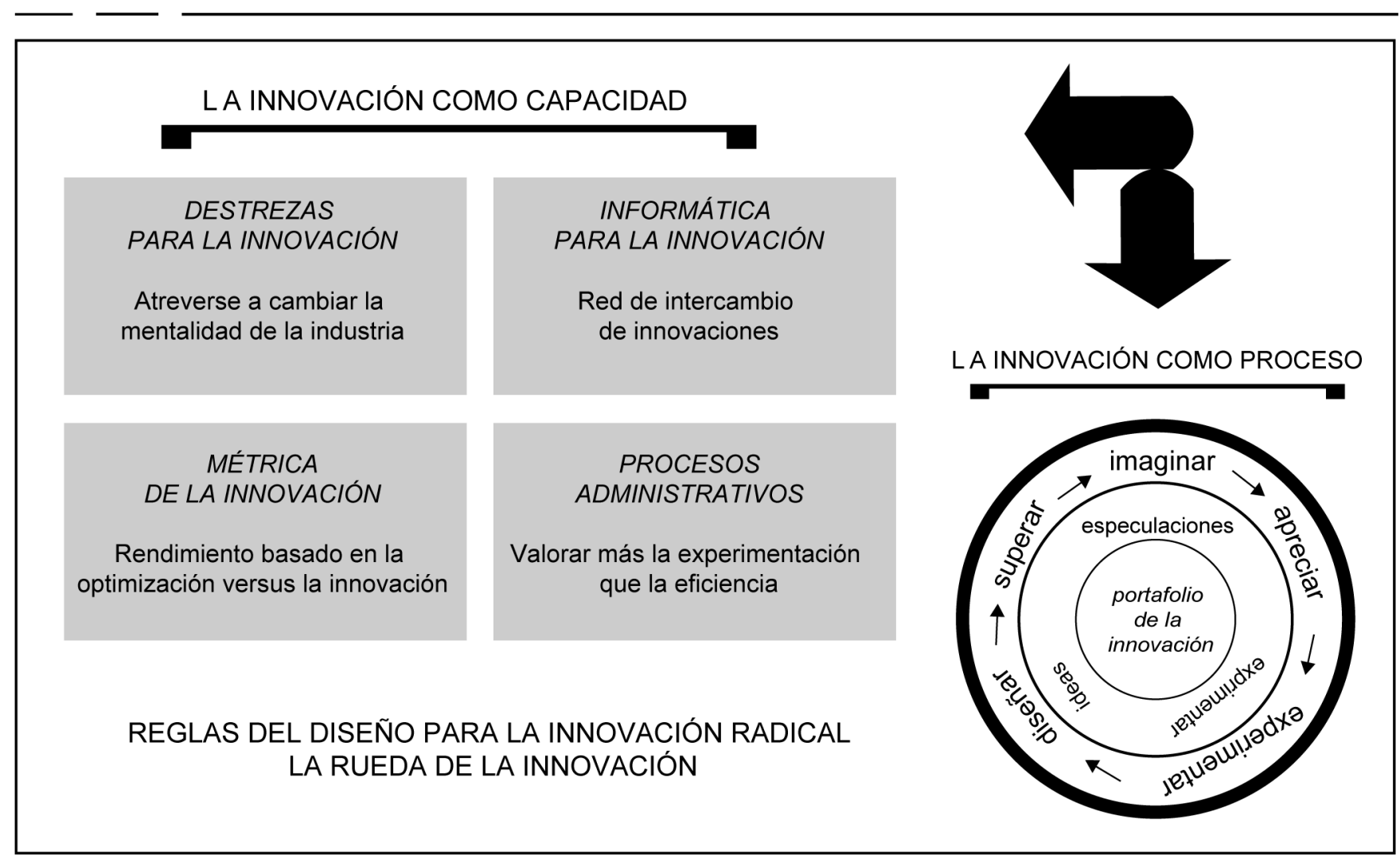

Fuente: HAMEL, Gary. Liderando la revolución. Bogotá: Norma 2000. p. 408

20 Ibíd., p. $72-73$. 
el que los elementos anteriores, tienen igualmente dimensiones explicativas:

\section{Innovación de oferta de mercado y de gestión y su relación con el marketing holístico}

En este orden de ideas, sería impensable la integración del consumidor de forma que desarrolle el papel de "prosumidor" ("el cliente especifica las necesidades y la empresa las satisface”) y participe en los procesos más vitales de mercadeo, tal como lo propone el Marketing holístico 22 .

El acceso a la información hace que los consumidores, aparte de tener mayor información para tomar decisiones, tengan la posibilidad de comparar con gran detalle en diferentes contextos geográficos y sectores productivos, las ofertas de mercado y por supuesto, informar sobre su nivel de satisfacción, con lo que el mismo consumidor retroalimenta directamente no solo a la empresa, sino también al mismo tiempo, a todos aquellos que acceden al sistema. Este hecho hace que:

- La comunicación empresa-consumidor ya no dependa exclusivamente de lo que la misma empresa desee informar; es decir, que no se tiene potestad sobre el "control absoluto" de la información ${ }^{23}$.

- La misma comunicación en red hace que entre consumidores se establezca un "diálogo" que a medida que se repite, trasciende la formalidad y se va tornando en un espacio en el que no solamente se comparte información, sino también opiniones y sentimientos, hasta que finalmente adquiere la connotación de "comunidad"24.

- El nuevo concepto de "comunidad en línea" tiene indudablemente un transfondo social que impacta el modo de relación empresa-consumidor, puesto que ya no se trata de consumidores aislados, sino de grupos sociales que demandan respuestas específicas como consumidores 25 .

En consecuencia, el intercambio empresa-consumidor, teniendo en cuenta lo más visible, tangible y concreto que es la oferta de mercado, hoy más que nunca, no se diseña a partir de cómo la empresa "interpreta las necesidades del consumidor", sino de la participación "activa" del mismo consumidor, quien "coparticipa" en la creación de valor de las ofertas de mercado ${ }^{26}$, lo cual reafirma lo dicho por Kotler:

La era de la información ha creado mercados hipercompetitivos. Los compradores están más al corriente de las ofertas competitivas, son más conscientes del precio y mucho más exigentes que en el pasado. El poder ha pasado de los fabricantes y minoristas a los consumidores, que ahora pueden definir qué quieren bajo la forma de productos y servicios personalizados, con precios, canales de distribución e incluso publicidad y promoción de ventas específicos 27 .

Pero ¿qué hacer frente al impacto que puede tener el consumidor en las ofertas de mercado, quien por su acceso a internet dispone de mayor información local, regional y global, la cual le permite asumir posturas críticas, argumentadas, y le dan suficientes elementos para asumir diferentes posturas frente al mercado?; ¿qué hacer frente a la falta de innovaciones reales para crear productos que marquen una diferencia tajante frente a la competencia? y ¿qué hacer frente a los modos de gestión convencional que priman en el mundo occidental?

Lo más sensato sería propugnar, en su orden, por un nuevo modo de relación empresa-consumidor, empresa-empleado y por nuevos modos de gestión; en una palabra, innovar.

Pero ¿qué tan dispuestas están las empresas a hacerlo? El nivel directivo empresarial en el que se ubica el poder de decisión ¿qué tanto estaría dispuesto a optar por alternativas más participativas y democráticas?

Todos estos interrogantes abren el camino para futuras investigaciones que faciliten precisar y retroalimentar aspectos determinantes para el diseño de estrategias empresariales, que permitan construir plataformas competitivas para la creación y entrega de valor, tal como lo propone Kotler con el concepto de Marketing holístico.

21 Ídem

22 KOTLER, El Marketing se mueve. Op. cit., p. 58 - 59.

23 PRAHALAD, C. K. y RAMASWAMY, Venkant. Cocreación de un valor unico con los clientes. En : Estrategia Corporativa. Barcelona: Deusto, 2006. p. 172

24 Ídem.

25 Ídem.

26 Ibid. 175-27.

27 KOTLER, El marketing se mueve, Op cit., p. 22 - 23. KOTLER, Ídem. 


\section{BIBLIOGRAFÍA}

- CÁMARA DE COMERCIO DE BOGOTÁ. Testimonios de gestión humana. Santa Fé de Bogotá D. C, 1999.

- GUILTINAN, Joseph y GORDON, Paul. Marketing. Bogotá, Mc Graw Hill, 2004. 6 ed.

- HAMEL, Gary. Liderando la revolución. Bogotá, Norma, 2000.

-HAMEL, Gary. "Innovación de gestión". Harvard Business Review. Febrero, 2006.

-KERIN, Roger, BERKOWITZ, Eric, HARTLEY, Steven, RUDELINS, William. Marketing. México, Mc Graw Hill, 2004.7 ed.

-KOTLER, Philip. Dirección de marketing. Edición del milenio. España, Prentice Hall, 2002.

- KOTLER, Philip. El marketing se mueve. Barcelona, Paidós, 2002.

- LAMB, Charles W Jr. Marketing. México, Thomson, 1998. 4 ed. .

- MONTAÑA, Jordi. Marketing de nuevos productos. Diseño, desarrollo y lanzamiento. Barcelona, Hispano Europea, 1990.

- MOLANO, Mauricio. De la calidad total a la calidad integral. Bogotá, Bancarias y Financieras, 1992.

- PRAHALAD, C. K. y RAMASWAMY, Venkant. Cocreación de un valor único con los clientes. En: Estrategia corporativa. Barcelona, Deusto, 2006.

- PRIDE William y FERREL, O C. Marketing: conceptos y estrategias. Bogotá, Mc Graw Hill, 1997. 9 ed.

- TAlayA, Agueda. Principios de marketing. Madrid, ESIC, 1996.

- ULRICH, Karl y ESPPINGER, Steven. Diseño y desarro$1 l o$ de productos. Enfoque multidisciplinario. México, Mc Graw Hill, 2004. 3 ed.

\section{Anexo A \\ Caso Organización Corona*}

\section{Antecedentes}

La necesidad de la transformación de la Organización Corona nace a partir de un conjunto de reflexiones en medio de un profundo cambio institucional en el país. Dicho cambio se originó en la proximidad de la apertura económica, y en la necesidad de buscar un espacio en la economía mundial que obligó a puntualizar varios interrogantes resumibles en cómo lograr una mayor productividad y competitividad para ser autosostenibles, mediante procesos de largo alcance; y si, en este orden de ideas, es posible utilizar conocimientos de otros países y/o los existentes en Colombia; así como revisar la manera de aplicarlos y la incidencia de dicha transformación en el ambiente organizacional ${ }^{1}$.

\section{Marco conceptual}

La Organización Corona define como marco de referencia conceptual para su transformación, la "organización"como aquel ente dinámico a partir del cual se anticipa, maneja y controla el cambio y que es fundamental en la medida en que de ella se deriva la calidad de vida de las personas que la integran, aparte del impacto que tiene en su entorno externo mediato e inmediato y cuya eficiencia y efectividad depende indudablemente de la calidad de su gestión, cuya teoría y práctica, se ha ido reconfigurando para dar respuesta al nuevo paradigma imperante en el mundo actual ${ }^{2}$.

Se crea conciencia sobre nuevos modos de pensamiento que reemplazan los de antes: una apreciación holística del mundo que permite ver la naturaleza como parte integral del ser humano; una mayor disposición hacia la apertura, la participación y la integración, en contraposición a modos autoritarios de confrontación y de competencia; una postura más realista frente a los avances de la ciencia y la tecnología al reconocer que por sí solas no permiten un mundo mejor, y finalmente,

\footnotetext{
* Fuente: CÁMARA DE COMERCIO DE BOGOTÁ. Testimonios de gestión humana. Santa Fe de Bogotá D. C.: 1999 . p.37 - 55.

1 Ibíd., 37-55

2 Ibíd., 38 - 39.
} 
el reconocimiento más importante quizá, de que es el ser humano con todo su potencial de creatividad y disposición para aprender, como el verdadero protagonista ${ }^{3}$.

Se reconoce igualmente la nueva tendencia mundial a la unidad y comunidad de intereses, que pone de manifiesto la integración, las alianzas, las redes de intercambio y resalta la importancia de pasar del tipo de liderazgo autoritario típico de organizaciones mecanicistas en las que el hombre es considerado a partir de sus debilidades, a un tipo de liderazgo acorde con organizaciones holísticas, integradas, en las que el ser humano es concebido a partir de sus fortalezas para construir ese bienestar general que permite hacer mejores las personas y la sociedad ${ }^{4}$.

\section{Propósitos}

Con base en el marco conceptual antes expuesto, la Organización Corona inició en 1989 un proceso de desarrollo de la calidad, en toda la organización, a partir de la experiencia preliminar realizada en 1983 en una de sus plantas de griferías, en la que se aplicó el desarrollo de procesos con el enfoque japonés de la calidad total y con los siguientes propósitos ${ }^{5}$ :

- Hacer la organización y sus empresas altamente eficientes y eficaces para proyectarse y crecer; capaces de aprender permanentemente; más sencillas, fluidas y abiertas, para responder a las demandas del entorno y satisfacer las necesidades de los clientes.

- Tener una cultura de trabajo centrada en el concepto de proceso (no en resultados) para facilitar respuestas más proactivas y reflexivas.

- Tener empleados que interioricen la responsabilidad, la dirección y el control y concurran por su motivación y satisfacción en el trabajo.

- Tener una organización con una misión compartida que le dé sentido, fuerza y motivación al trabajo de cada empleado y una cotidianidad gratificante al valorar el aporte individual al esfuerzo colectivo.

- Tener una organización con el ambiente propicio para que cada empleado pueda manifestar su potencial creativo.
- Tener cada vez mejores niveles de formación y capacitación para lograr un desarrollo integral de los empleados tanto en lo personal, como en lo mental y manual. - Fortalecer el valor de la responsabilidad social sobre el cuidado del medio ambiente y el servicio a la comunidad.

\section{Características del proceso de desarrollo de la calidad}

Las pautas para adelantar el proceso de desarrollo de la calidad fueron 6 :

- La reflexión deliberada sobre la proximidad de la apertura, no como respuesta a una crisis.

- Diseño interno del método de investigación-acción para adelantar el proceso aplicado directamente en cada sitio de trabajo.

- Liderar, estructurar, programar y manejar la dirección de todo el proyecto, con el apoyo de asesores externos en algunos aspectos puntuales.

- La dirección revisó y reflexionó sobre los valores y los modelos mentales sobre la gestión, la calidad del trabajo, la orientación al cliente, para conservar aquellos que fueran útiles para el proceso y descartar aquellos que no lo fueran.

- El proceso de cambio se nutre con conocimientos de gestión propios y de la misma experiencia en su aplicación, así como de bibliografía sobre el tema y del aprendizaje de otras empresas en Estados Unidos, Europa y Japón.

-Crear una unidad corporativa de calidad, como facilitadora del proceso a través de asesoría, diseño de procesos educativos y diseño de material, entre otros.

En conclusión, las grandes transformaciones de la Organización Corona, se centran en dos aspectos fundamentales: el modo de gestión y la forma como son asumidas las personas dentro de la organización.

Una gestión basada en la creencia de la autonomía, de antemano supone personas críticas, reflexivas, capaces de autoregularse y concentrar esfuerzos alrededor de aquellos propósitos que hacen evidente que su contribución es indispensable y que además están en la capa-

3 Íbid., 39 - 40.

4 Íbíd., 41.

5 Íbíd., 41, 42, 43, 44.

6 Íbíd., 44, 45, 46. 
cidad de mejorar porque se tiene una visión de proceso, que trasciende lo puntual, donde el mismo trabajo con el todo y sus partes lo retroalimenta para una mirada que va mucho más allá de lo inmediato.

El hecho de deliberar, reflexionar y aportar al mejoramiento del trabajo, rescata el potencial y permite la construcción de ambientes en los que se hace más probable el pensamiento y la acción creativa. Pero sobre todo, la sensación de pertenecer, integrarse y tener proximidad social en el contexto laboral, es uno de los aspectos inherentes a cualquier ser humano, que sin duda motiva y hace que ese bienestar tan buscado por cualquier persona está en aquel lugar en el que pasa la mayor parte del tiempo, lo que para el caso de Colombia es de gran importancia por el carácter gregario que nos distingue.

La manera de adelantar el cambio gira alrededor de las características propias de la cultura de la organización, para que cada etapa sea coherente y configure una acción guiada por los principios que enmarcan el modo de asumir la organización y su gente, tal como se propone desde el marco de referencia conceptual.
Los conocimientos y experiencias sobre gestión, tanto propios como tomados de otros países, son cuidadosamente pensados, diseñados, planeados y aplicados; en una palabra, son adaptados, para dar ese sentido integrador y de totalidad que involucra y al mismo tiempo facilita una realimentación cercana e individual en cada sitio de trabajo, lo que aparte de capacitar y desarrollar habilidades, es un reconocimiento en sí de la importancia del aporte de cada cual.

Finalmente, es relevante hacer evidente que el estilo de dirección participativo es decisivo para la transformación y estimuló realmente la noción de proceso y mejoramiento desde la perspectiva de este modo de gestión.

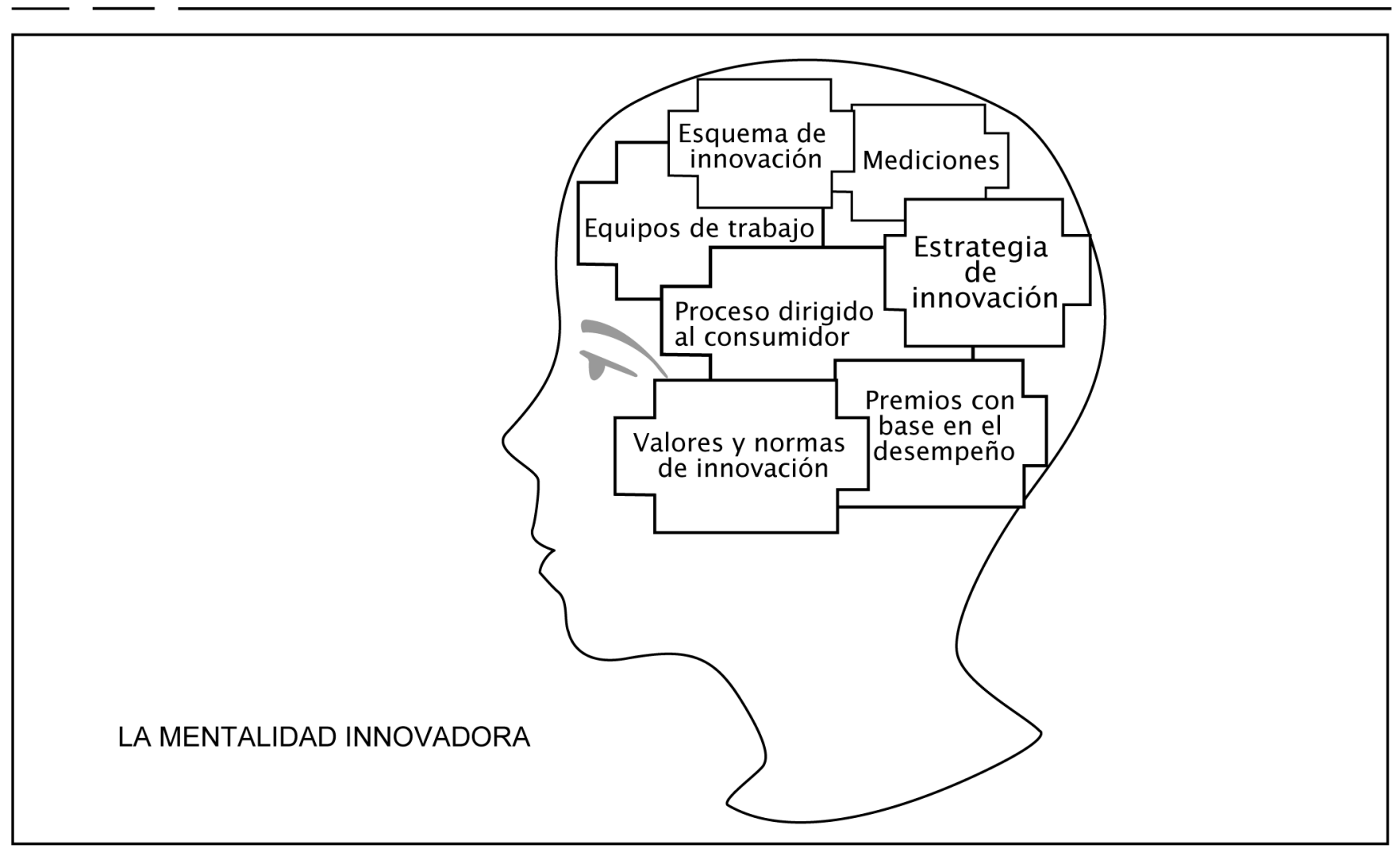

Fuente: http://images.google.com.co/images?hl=es\&q=innovacion\&gbv=2 